\title{
Nevus Comedonicus Syndrome
}

\author{
Pravesh Yadav, Vibhu Mendiratta, Shiwangi Rana, Ram Chander
}

\begin{abstract}
A case of nevus comedonicus syndrome with atypical cutaneous presentation (widespread involvement without any particular pattern, midline lesions involving lower abdomen and involvement of bilateral pinna), and some unusual skeletal (adduction deformity involving bilateral metatarsal along with medial deviation at the level of tarsometatarsal joint), central nervous system (agenesis of corpus callosum with a interhemispheric cyst), visceral (pancreatic cyst) and neurological manifestations have been illustrated.
\end{abstract}

Key Words: Comedo nevus, nevus comedonicus syndrome, nevus comedonicus
From the Department of Dermatology and Sexually Transmitted Diseases, Lady Hardinge Medical College and Suchita Kriplani Hospital, Shaheed Bhagat Singh Marg, Delhi - 110 001, India

\author{
Address for correspondence: \\ Dr. Pravesh Yadav, \\ RZ-97, Phase-III, \\ Prem Nagar, Najafgarh, \\ New Delhi - 110 043, India. \\ E-mail:rao.pravesh@gmail.com
}

What was known?

- Nevus comedonicus syndrome is a rare syndrome with extracutaneous manifestations.

- Commonly involved sites for comedo nevus include face, neck, upper arm, chest and abdomen in a grouped, band-like lesions, or linear pattern along lines of Blaschko.

- It can involve various systems including central nervous system, skeletal, opthalmological, neurological, spinal abnormality.

\section{Introduction}

Nevus comedonicus (NC) or comedo nevus refers to closely arranged, grouped, often linear, slightly elevated papules that have at their center keratinous plugs. It may be present since birth or appear later. The term NC syndrome is used for comedo nevus presenting in association with extracutaneous manifestations which may include central nervous system (CNS), skeletal, opthalmological, neurological, and spinal abnormality. We herein report the case of a child with NC syndrome with associated skeletal, CNS and neurological abnormalities in addition to a pancreatic cyst.

\section{Case Report}

Dermatology opinion was sought for a 13-year-old boy for multiple skin-colored raised lesions with black dots in bilateral armpits, which were present since birth and over bilateral pinna for 3-4 years. The lesions were asymptomatic except for occasional muco-purulent discharge from lesions over the armpits. He had history of few episodes of generalized seizure at the age of 2 months, the cause of which could not be ascertained

\begin{tabular}{|l|l|}
\hline \multicolumn{2}{|c|}{ Access this article online } \\
\hline Quick Response Code: & \\
\hline & \\
\hline
\end{tabular}

at that time. The patient also had delayed developmental milestones with below average performance at school. There was no history of similar lesions in the family. His mother had lichen planopilaris over the scalp.

Examination revealed multiple open comedones interspersed with few skin-colored nodules topped with comedones and few linear scars over bilateral axilla [Figures 1 and 2]. Comedones were also present in a linear arrangement over bilateral pinnae and lower abdomen in the midline extending from just above the umbilicus to the pubic symphysis [Figure 2]. There was shortening and flexion deformity involving the first digit of left hand [Figure 3]. Mucosal examination was normal. Evaluation of ophthalmic, otorhinolaryngeal, dental and endocrinological systems was normal. Pediatric evaluation for physical growth was normal for age. Intelligence quotient (IQ) assessment revealed moderate mental retardation (score 10).

Histopathology from the comedonal lesion revealed large epidermal invagination along with hyperkeratosis, focal keratotic plugging and increased basal cell pigmentation in the epidermis. Dermis was unremarkable [Figure 4]. Radiograph of hands showed small bilateral pisiform bones and increased scapho-lunate joint space in the right hand [Figure 5]. Radiograph of feet showed adduction deformity involving bilateral metatarsals along with medial deviation at the level of bilateral tarsometatarsal joints [Figure 5]. Ultrasound of the abdomen showed a cyst of size $13 \times 11 \mathrm{~mm}$ in pancreatic body. Computerized tomography scan of spine and head revealed corpus 


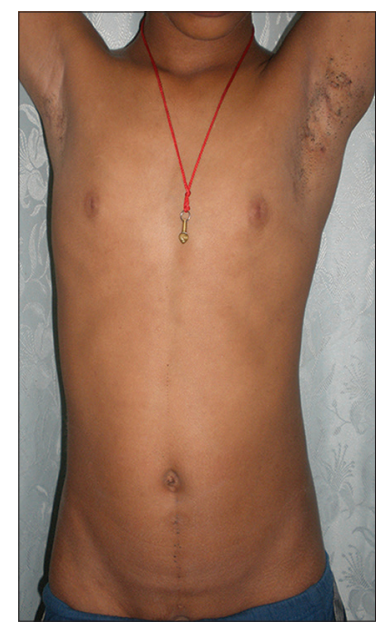

Figure 1: Multiple open comedones and nodules involving bilateral axilla and lower abdomen in the midline extending from just above the umbilicus to the pubic symphysis

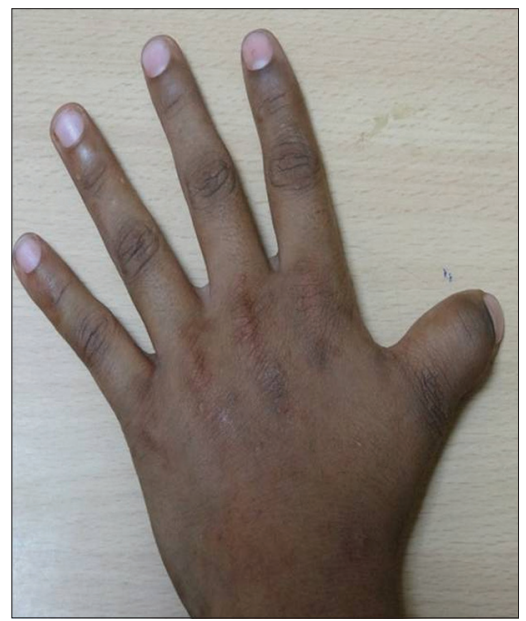

Figure 3: Shortening and flexion deformity in the $1^{\text {st }}$ digit of left hand

callosum agenesis with a single interhemispheric cyst [Figure 6]. Biochemical investigations revealed vitamin $\mathrm{D}_{3}$ deficiency $(15.69 \mathrm{ng} / \mathrm{ml}$ ) (normal range 30-100 ng/ml). Other hematological and biochemical investigations were normal.

Based on these findings, a diagnosis of NC syndrome was made. Tretinoin $(0.025 \%)$ cream was given for local application and within 2 weeks, there was good response with partial clearance of comedones over pinnae and axillae.

\section{Discussion}

NC has been described in association with various extracutaneous manifestations and a term "nevus comedonicus syndrome" has been used for this. Noncutaneous developmental abnormalities include skeletal malformation (absent fifth finger, trichilemmal cysts, rudimentary toe, scoliosis), eccrine spiradenoma and hidradenoma, bilateral follicular basal cell naevus, Alagille syndrome, CNS abnormalities (brain dysgenesis,

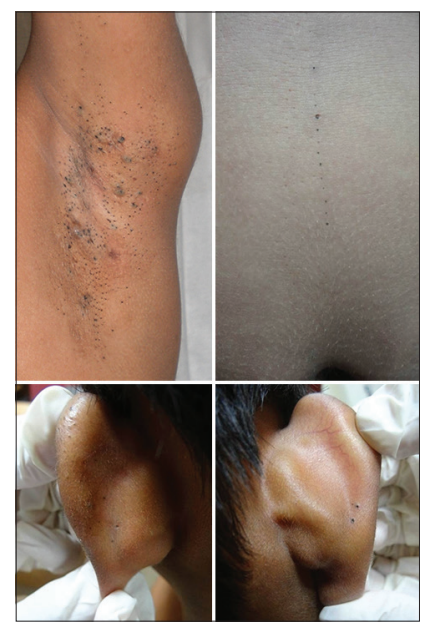

Figure 2: Closer view of left axilla and abdomen lesions and bilateral ear lesions

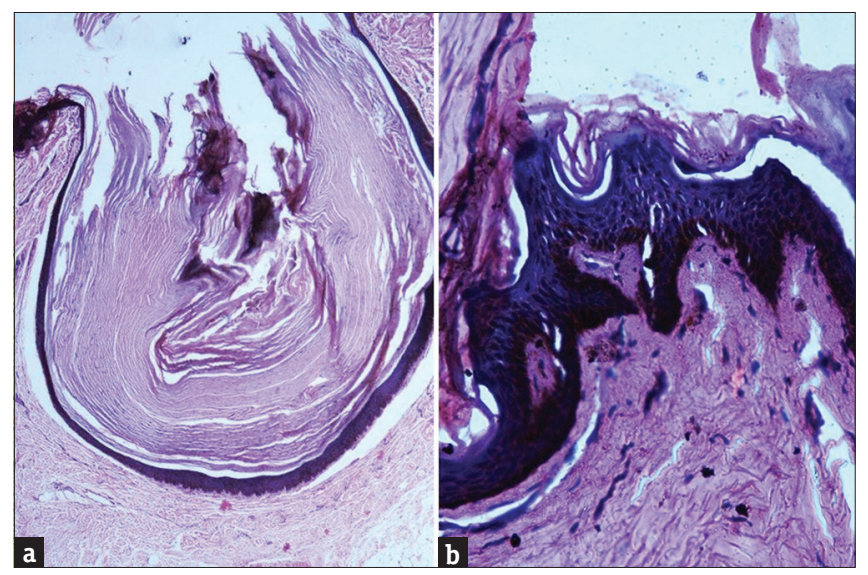

Figure 4: (a) Histopathology showing hyperkeratosis, focal keratotic plugging and increased basal cell pigmentation in the epidermis. Dermis was unremarkable. ( $\mathrm{H}$ and $\mathrm{E}$, $\times 100$ ) (b) High power view showing large epidermal invagination. ( $\mathrm{H}$ and E, x400)

microcephaly, Sturge-Weber syndrome), multiple basal cell carcinoma, ipsilateral polysyndactyly and bilateral oligodontia, ipsilateral cataract, and trichilemmal cysts. ${ }^{[1]}$

Recently, Happle has used the term "the epidermal naevus syndromes" to include at least six separate disorders including comedo naevus syndrome in addition to those with extracutaneous manifestations with verrucous epidermal nevus and nevus sebaceous. ${ }^{[2]}$ Morphologically, NC lesions consist of closely arranged papules, often with a central, dark, firm hyperkeratotic plug. Secondary inflammatory changes such as papules with irregular borders, nodules, cysts, pustules and abscesses are often seen, and scarring may be significant. Common sites reported to be involved include face, neck, upper arm, chest and abdomen. The pattern of involvement has been commonly described as grouped, band-like lesions, linear pattern along line of Blaschko or extensive unilateral lesions. ${ }^{[3]}$ In the present case, the patient had a widespread involvement without any particular pattern. The patient also had midline lesions involving lower abdomen and involvement of bilateral 


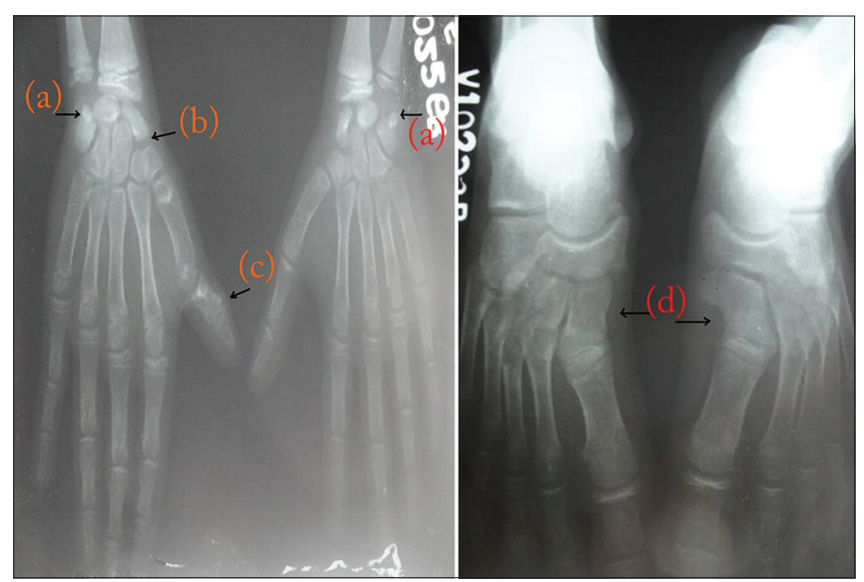

Figure 5: Radiograph of hands showing small bilateral pisiform (a) and increased scapho-lunate joint space in the right hand (b). Proximal phalanx of left first digit shows fore-shortening with medullary widening and cortical irregularity (c). Radiograph of feet showing adduction deformity involving bilateral metatarsal along with medial deviation at the level of tarsometatarsal joint (d)

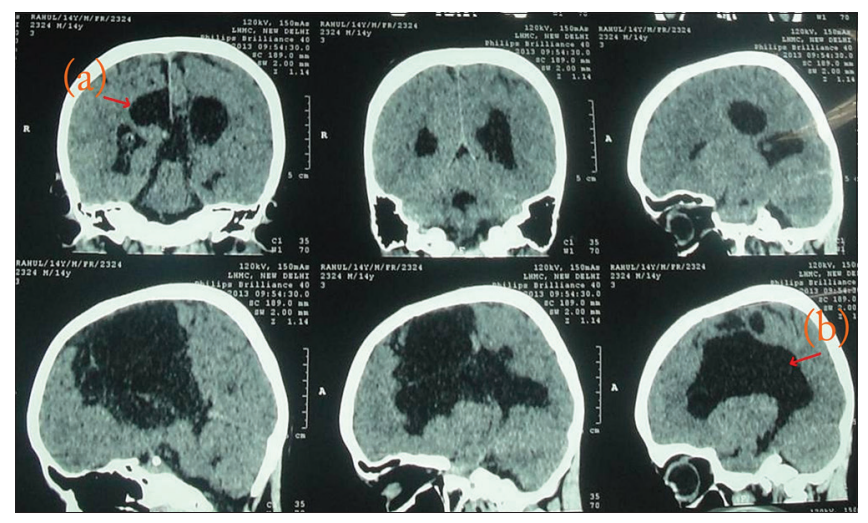

Figure 6: CT scan of head showing corpus callosum agenesis (a) with interhemispheric cyst (b)

pinna which have not been reported previously to the best of our knowledge.

Various CNS abnormalities reported in association with comedo nevus include cerebral anomalies, brain dysgenesis and microcephaly. Our patient had agenesis of corpus callosum with an interhemispheric cyst with low IQ, which is new to the literature. Among the skeletal abnormalities, polysyndactaly, ${ }^{[4]}$ syndactly, chinodactyly, rudimenatry toe, ${ }^{[5]}$ bone hypertrophy, bone cyst, kyphosis, scoliosis, spina bifida and vitamin D-resistant rickets ${ }^{[6]}$ are the one which has been recently reported. In our case, the patient had adduction deformity involving bilateral metatarsal along with medial deviation at the level of tarsometatarsal joint. Small bilateral pisiform and increased scapho-lunate joint space was present in the right hand. Involvement of visceral organs in the form of a pancreatic cyst has also not been reported previously, however, a case of "Alagille syndrome" ${ }^{[7]}$ has been reported with cardiac and liver abnormality.

Surgical excision with tissue expansion can be done for smaller lesions, superficial dermabrasion and regular comedone extraction if the lesions are extensive. Among the medical options, topical retinoic acid, $12 \%$ ammonium lactate, tacalcitol and tazarotene $0.05 \%$ with calcipotriene $0.005 \%$ daily have also been used effectively. Oral isotretinoin is useful for extensive inflamed acneiform naevi.

The reported case is a rare syndrome with unusual skeletal, CNS and visceral involvement that adds to the associations that have been reported with NC syndrome. Furthermore, the pattern and distribution of NC is also new to the literature.

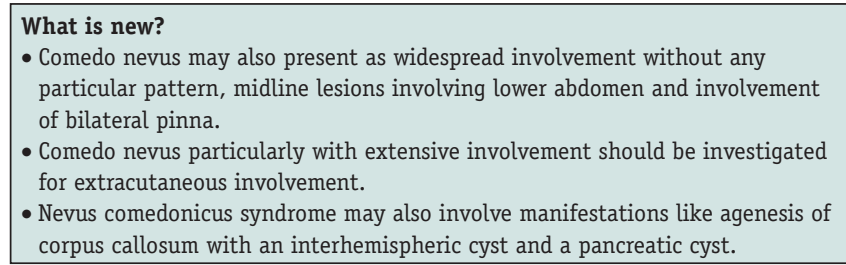

\section{References}

1. Cockerell CJ, Larsen F. Benign epidermal tumors and proliferations. In: Bolognia JL, Joseph LJ, Rapini RP, editors. Dermatology. $2^{\text {nd }}$ ed. India: Mosby; 2009. p. 1661-80.

2. Happle R. The group of epidermal nevus syndromes. Part I. Well defined phenotypes. J Am Acad Dermatol 2010;63:1-22;quiz 23-4.

3. Guldbakke KK, Khachemoune A, Deng A, Sina B. Naevus comedonicus: A spectrum of body involvement. Clin Exp Dermatol 2007;32:488-92.

4. Kaliyadan F, Nampoothiri S, Sunitha V, Kuruvilla VE. Nevus comedonicus syndrome--nevus comedonicus associated with ipsilateral polysyndactyly and bilateral oligodontia. Pediatr Dermatol 2010;27:377-9.

5. Alpsoy E, Durusoy C, Ozbilim G, Karpuzoğlu G, Yilmaz E. Nevus comedonicus syndrome: A case associated with multiple basal cell carcinomas and a rudimentary toe. Int $\mathrm{J}$ Dermatol 2005;44:499-501.

6. Seo YJ, Piao YJ, Suhr KB, Lee JH, Park JK. A case of nevus comedonicus syndrome associated with neurologic and skeletal abnormalities. Int J Dermatol 2001;40:648-50.

7. Woods KA, Larcher VF, Harper JI. Extensive naevus comedonicus in a child with Alagille syndrome. Clin Exp Dermatol 1994;19:163-4.

How to cite this article: Yadav P, Mendiratta V, Rana S, Chander R. Nevus comedonicus syndrome. Indian J Dermatol 2015;60:421.

Received: March, 2014. Accepted: November, 2014.

Source of support: Nil, Conflict of Interest: Nil. 